DOI: 10.19085/journal.sijbpg030801

\title{
An Analysis of Edwin B. Wilson's Secret, Second Review of the A Treatise on Probability in 1934: How it demonstrated that Keynes's Theory of Probability was an Interval Valued Approach to Probability and not an ordinal theory
}

\author{
Michael Emmett Brady \\ Lecturer, College of Business Administration and Public Policy, Department of Operations Management, \\ California State University, Dominguez Hills, Carson, California, USA. \\ (c) Scholedge International Journal of Business Policy \& Governance (ISSN 2394-3351), Vol.03, Issue 08 (2016) pg110-121. \\ Published by: Scholedge R\&D Center [http://www.thescholedge.org/journals/] [Email: editorial@thescholedge.org]
}

\begin{abstract}
Wilson admitted in private correspondence in 1923 with Francis Ysidro Edgeworth that he should not have attempted his review of the A Treatise on Probability (1921) in 1923.The reason Wilson gave to Edgeworth in his correspondence was exactly the same as the reason Edgeworth gave Wilson as the reason Edgeworth was writing to Wilson-a lack of understanding about what Keynes was doing in Part II of the A Treatise on Probability. What Keynes had done, of course, was revolutionary. Keynes had built on the earlier, logical theory of Boole .Keynes erected a general theory of probability where numerical probabilities appeared as a special case when the weight of the evidence, $w$, defined on the unit interval[0,1], where $\mathrm{a} w=1$ defined a complete evidence set upon which to base a decision maker's estimates of probability, equaled, approximated or approached 1 .w measured the completeness of the evidence. If the weight of the evidence equaled 1 and the decision maker had linear probability preferences, then precise, exact, numerical probabilities could be calculated.
\end{abstract}

Keynes 's axiom system in Part II of the A Treatise on Probability was set up to deal with both interval valued probabilities, which are non additive, and numerical(cardinal) probabilities, which are additive .Non additive probabilities are not subject to the mathematical laws of the probability calculus, the addition rule and the multiplication rule. Keynes used interval valued estimates to deal with the problems of uncertainty and ignorance, where missing relevant information, data, knowledge, or evidence meant that a decision maker could not use numerical probabilities because Keynes's weight of the evidence variable, $w$, was less than 1.Only in the case of a complete information set could numerical probabilities or a probability distribution be specified.

In 1934, Wilson published a note titled, Boole's Challenge Problem, in the Journal of the American Statistical Association. It is actually a disguised, camouflaged second review of J M Keynes's A Treatise on Probability that deals with Keynes's Part II again. This time, Wilson gets the technical analysis correct right. 
Wilson's note, although he himself had no idea about why dealing with conditions of uncertainty and ignorance was relevant when making a decision, totally and completely destroys the logical and intellectual foundations erected by G. L. S.Shackle and Paul Davidson, as well as Jochen Runde, Shiela Dow,Rod O'Donnell,Tony Lawson,Anna Carabelli,Robert Skidelsky, Gay Meeks,Bradley Bateman,Donald Gillies , and many other Post Keynesians,Institutionalists,and Keynesian Fundamentalists, who have claimed, on the basis of papers published by Frank Ramsey and Richard Braithwaite, for nearly 40 years that J M Keynes's theory in the A Treatise on Probability is an ordinal theory that could only be applied some of the time or has to be interpreted as a relative frequency theory to make an sense out of it (Davis, Winslow).

The two books that supposedly claim to deal with Keynes's approach to uncertainty, The Philosophy of Keynes' Economics: Probability, Uncertainty, and Convention,2003,edited by Runde and Mizuhara,and Fundamental Uncertainty,2011,edited by Marzetti Dall'Aste Brandolini and Scazzieri contain no mention of either George Boole or interval valued probability, Thus, they have nothing to say about Keynes's interval valued approach to probability.

\section{Section1.Introduction}

Wilson's 1923 review of the A Treatise on Probability (TP;1921) appeared in the journal,Bulletin of the American Mathematical Society.His 1934 note appears in the Journal of the American Statistical Association.The earlier 1923review is not mentioned in the 1934 note.The only sources listed by Wilson are Keynes's TP and a book by Yule which was cited by Keynes in a footnote on p.161 of the TP as containing a chapter showing how to work through "approximation" problems a la Boole.The entire 1934 note deals with Keynes's application of Boole's approach in Part II of the TP.The note absolutely nothing to do with George Boole's work in the The Laws of Thought(1854).

Consider the following claims made by Wilson:

“Boole's Challenge Problem is discussed by J. M. Keynes in his Treatise on Probability, pp. 186-189, where some of the history of the problem is given and a solution in terms of Keynes's special notation (sic). It may be of interest to show that the problem yields very easily to the most elementary methods in customary notation."(Wilson,1934,p. 301)

There are some severe intellectual problems here with Wilson's first paragraph .First ,Keynes discussed the Challenge Problem, using Boole's approach, first on pp.161-163 of the 1921 edition in chapter 15 ,as well as working out a number of derivative problems using his conditional probability approach on pp.186-194.Boole's problem X , on p.192,was modified by Keynes to serve as the foundation for all of Part III of the TP. Wilson is hiding from the reader that he only figured out how to work out one of the various versions of the Challenge problem by making use of Yule's bookrecommended to the reader by Keynes.

Secondly, Wilson then makes the following claim:

"It may be of interest to show that the problem yields very easily to the most elementary methods in customary notation.”(Wilson, 1934,p.301) 
Of course ,the customary notation was used by Keynes in his chapter 15 exposition.Wilson's "customary notation" exposition is simply a minor variation of the version of Keynes's chapter 15 problem .

Thirdly, Wilson's claim that “...the problem yields very easily..." directly conflicts with his correspondence in 1923 with Edgeworth where he statedthat he had no idea about how to deal with the analysis in Part II of the TP.

Fourthly ,Wilson demonstrates that, while he finally understands Keynes's technical approach to indeterminate, interval valued probability problems, he had absolutely no understanding of why one has to use interval estimates to deal with the problems of uncertainty and ignorance.He makes the following assessment:

"One may well wonder what importance there is, other than that of satisfying intellectual curiosity, in stating or solving an indeterminate problem. If the problem arises in practice the statistician should realize that he needs to accumulate counts not only of $\alpha+\beta$ and $\alpha+\gamma$ but of $\alpha$, not only of $\alpha_{1}+\beta_{1}$ and $\alpha_{1}+r_{1}$ but of $\alpha_{1}$. It is indeed difficult to see how a person should be able to say that on $N$ trials $E$ accompanies $A_{1}, \alpha_{1}+\beta_{1}$ times and $A_{2}, \alpha_{1}+r_{1}$ times and is absent if $A_{1}$ and $A_{2}$ areboth absent without being able also to make the enumeration of the $\alpha_{1}$ times when $E$ occurs with both $A_{1}$ and $A_{2}$; and so, too, if we know the probability of $A_{1}$ and of $A_{2}$ individually we should ordinarily, except for carelessness, be able to give the probability of both $A_{1}$ and $A_{2}$ together -whether a priori or a posteriori. Any statistical consultant knows, however, from his own experience that investigators not trained in the logic of statistics do often come to him with only partial enumerations of the necessary elements to make their problem definite and cannot al- ways go back and pick up the missing information; it then becomes necessary to do the best one can with the data available.”(Wilson,1934,p.304)

This leads to our final conclusion, which is that Wilson was misrepresenting his knowledge to the readers in his 1934 article or he was misrepresenting his knowledge to Edgeworth in his 1923 exchange over the TP's Part II.

It is also clear that Wilson believes that there can never be any such thing as missing data or information except due to individuals who have not been properly trained in statistics.

\section{Section 2. Wilson's results compared and contrasted to the claims of the "Keynesian Fundamentalists", such as Skidelsky ,Carabelli Meeks,and O’Donnell}

Skidelsky gives the following account of what he believed Keynes 's decision theory in the A Treatise on Probability was:

"Any account of Keynes's contributions to economics must start with his distinctive theory of probability. 
In his Treatise on Probability (1921), he sought to rescue the ordinary language (or ordinal) use of probability from the statistical (or cardinal) theory of probability. He put forward a logical theory of probability, of which the then dominant frequency theory was a special case. In ordinary life, we will often have enough evidence to say that something is more likely to happen than not, without having enough evidence to say it is three times as likely..."(Skidelsky,2016,Preface)

and

"In his Treatise on Probability (1921), Keynes set out an alternative: the landscape of chance. First, there is cardinal or measurable probability, e.g. 'There is a one in six chance of your house catching fire in the next year'. This frequency view of probability partly derives from games of chance, partly from invariable connections found in the natural, and some parts of the human, world. 'In actual reasoning... exact measures [of this kind] will occur comparatively seldom', Keynes wrote ${ }^{2}$. Second, is ordinal probability, in which we have some evidential basis for believing that something is more or less likely to occur without being able to attach numbers to 'more' or 'less'. Most risk assessments used by non-financial firms are based on this informal procedure. However, there is a residual category of 'unknown probabilities', in which our evidence is too scanty even to say that something is 'more likely than not, or less likely than not, or as likely as not'. ${ }^{3}$ For Keynes, probability is the hypothesis on which it is reasonable for us to act in conditions of limited knowledge. ${ }^{4}$ There is no presumption that our knowledge will be sufficient to give us calculable probabilities.

Here is Keynes's canonical statement, from a 1937 essay:

By 'uncertain' knowledge, let me explain, I do not mean merely to distinguish what is known for certain from what is only probable. The game of dice is not subject, in this sense to uncertainty; nor is the prospect of a Victory bond being drawn...." (Skidelsky, 2010 ,p.8).

The Skidelsky account above, which is a summary of claims made in his three volume biography of Keynes, heavily influenced R. O'Donnell's (as well as practically all other Post Keynesian and Institutionalist economists) more expansive argument that we shall present below in section 3.Note that the Boole-Keynes concept of interval valued probability appears nowhere in the work of any Post Keynesian or Institutionalist economist in the 2oth century.

Consider next the fundamental error made by Skidelsky above ,where he confuses Keynesian indeterminate probabilities, based on an interval valued approach first applied by George Boole , with unknown probabilities. The same error haunts all of O'Donnell's work in this area going back over 35 years:

“However, there is a residual category of 'unknown probabilities', in which our evidence is too scanty even to say that something is 'more likely than not, or less likely than not, or as likely as not'. ${ }^{3}$

Let us carefully analyze Keynes' entire statement below:

"This leads up to a contention, which I have heard supported, that, although not all measurements and not all comparisons of probability are within our power, yet we can say in the case of every argument whether it is more or less likely than not. Is our expectation of rain, when we start out for a walk, always more likely than not, or less likely than not, or as likely as not? I am prepared to 
argue that on some occasions none of these alternatives hold, and that it will be an arbitrary matter to decide for or against the umbrella. If the barometer is high, but the clouds are black, it is not always rational that one should prevail over the other in our minds, or even that we should balance [ authors emphasis-Keynes is referring to interval estimates here and not ordinal probabilities],- - though it will be rational to allow caprice to determine us and to waste no time on the debate."(Keynes,TP,p.32)

Now all throughout chapter 3 of the TP, Keynes made a series of references to intervals (see pp. 22,23-24,29,21-32,34-35).

Daniel Ellsberg, on pp.119-123 of his 1962 dissertation, published in 2001, showed why the problem above is a problem of interval estimation where the probabilities must be indeterminate. Comparison is not possible because the intervals overlap .A simple example is the attempt to compare the two intervals [.52,.61] with [.49,.58].It is not possible to say that one is greater than or less than the other, or as likely as not. That is because the intervals are indeterminate .It has nothing to do with unknown probabilities.

We continue with another example:

"At any rate I aim here at dealing with probability in its widest sense, and am averse to confining its scope to a limited type of argument. If the opinion that not all probabilities can be measured seems paradoxical, it may be due to this divergence from a usage which the reader may expect. Common usage, even if it involves, as a rule, a flavour of numerical measurement, does not consistently exclude those probabilities which are incapable of it. The confused attempts, which have been made, to deal with numerically indeterminate probabilities under the title of unknown probabilities, show how difficult it is to confine the discussion within the intended limits, if the original definition is too narrow.(Author' s emphasis added)

14. I maintain, then, in what follows, that there are some pairs of probabilities between the members of which no comparison of magnitude is possible; that we can say, nevertheless, of some pairs of relations of probability that the one is greater and the other less, although it is not possible to measure the difference between them; and that in a very special type of case, to be dealt with later, a meaning can be given to a numerical comparison of magnitude. I think that the results of observation, of which examples have been given earlier in this chapter, are consistent with this account.

By saying that not all probabilities are measurable, I mean that it is not possible to say of every pair of conclusions, about which we have some knowledge, that the degree of our rational belief in one bears any numerical relation to the degree of our rational belief in the other; and by saying that not all probabilities are comparable in respect of more and less, I mean that it is not always possible to say that the degree of our rational belief in one conclusion is either equal to, greater than, or less than the degree of our belief in another." (Keynes,1921,pp.35-36).

Again, take the simple example used above, [.52, .61] with [.49,.58]. Keynes 's conclusion is so obvious that it is amazing that Ramsey, and Skidelsky, who bases his entire assessment of the TP on the two Ramsey reviews, could go so wrong: 
"... it is not always possible to say that the degree of our rational belief in one conclusion is either equal to, greater than, or less than the degree of our belief in another."(Keynes,1921, p.32)

"On this theory it is easy to see why comparisons of more and less are not always possible. They exist between two probabilities, only when they and certainty all lie on the same ordered series. But if more than one distinct series of probabilities exist, then it is clear that only those, which belong to the same series, can be compared. If the attribute 'greater' as applied to one of two terms arises solely out of the relative order of the terms in a series, then comparisons of greater and less must always be possible between terms which are members of the same series, and can never be possible between two terms which are not members of the same series. Some probabilities are not comparable in respect of more and less, because there exists more than one path, so to speak, between proof and disproof, between certainty and impossibility; and neither of two probabilities, which lie on independent paths, bears to the other and to certainty the relation of 'between' which is necessary for quantitative comparison”.(Keynes,1921,p.37)

Again , simply consider the two intervals specified above. Only within each interval (series) could comparisons be made .Comparisons can't be made between the two intervals or series of numbers. That is because the two probabilities are indeterminate.

Skidelsky's failure to recognize that there is no such third category as unknown probability, and that what Keynes is talking about is Boole's indeterminate probabilities, is fatal to Skidelsky's entire assessment of the TP.

Neither Meeks nor Carabelli do any better than Skidelsky.

Meeks claims the following:

"Ordinal ranking of probabilities will sometimes be elusive too (as in comparing propositions each based on a different type of evidence... Nor is it always possible even to make comparisons with a 50:50 benchmark."(Meeks,2003, p.30). She then fails to understand that the quotation she gives is dealing with interval estimates and not ordinal estimates.

"Is our expectation of rain, when we start out for a walk, always more likely....or less likely....or as likely as not? I am prepared to argue that on some occasions none of these alternatives hold... (Keynes, p.32)." (Meeks, 2003, p.30).Only the case of overlapping interval estimates satisfies Keynes's problem description.

Carabelli makes the following claims:

"To show Keynes's attitude to measurement and comparison of probability, I start from his manifesto

in TP. Keynes has a three-fold conception of probability:

I maintain, then, in what follows, that there are some pairs of probabilities between the members of which no comparison of magnitude is possible; that we can say, nevertheless, of some pairs of relations of probability that one is greater and the other less, although it is not possible to measure the difference between them; and that in a very special type of case, to be dealt with later, a meaning can be given to a numerical comparison of magnitude (TP: 36) 
Reversing Keynes's order, I call his first case, CASE-III; his second, CASE-II and his third, CASE-I.

Hence

“CASE-I: numerical comparison of probabilities

CASE-II: quantitative comparison of probabilities in terms of equal, more or less (unequal)

CASE-III: non quantitative comparison of probabilities." (Carabelli,2009, p.17-18)

Her CASE-III represents Keynes's indeterminate , interval valued probabilities that overlap. She spends pages 17-30 of her article trying to give her own interpretation, which makes no sense at all and will result in complete confusion for anyone who tries to figure out what it is that she thinks she is doing. On p.21, she cites what she calls Keynes's "Umbrella Dilemma" problem:

“Keynes's second example which I will jokingly call the 'umbrella dilemma' is the following:

"Is our expectation of rain, when we start out for a walk, always more likely than not, or less likely than not, or as likely as not? I am prepared to argue that on some occasions none of these alternatives hold, and that it will be an arbitrary matter to decide for or against the umbrella. If the barometer is high, but the clouds are black, it is not always rational that one should prevail over the other in our minds, or even that we should balance them, - though it will be rational to allow caprice to determine us and to waste no time on the debate (TP: 32)"( Carabelli,2009,p.21)

Of course, this is a simple application of Boole's indeterminate, interval valued probability approach, adapted by Keynes in the TP, due to an overlap in the intervals.

Nowhere in any article written by Carabelli, or anyone else connected with her ,O'Donnell, Meeks, or Skidelsky, will one find any mention of Boole or Theodore Hailparin, who showed exactly what it was that Boole and Keynes were doing , and generalized his approach.

The result is that the literature on Keynes's since the late 1970's is a complete, intellectual mess.

O'Donnell's misinterpretation , as with Carabelli's ,is based directly on Meek's and Skidelsky's flawed positions. Consider either of the following two summaries of O'Donnell's assessment of Keynes's approach in the TP:

"... .only a very restricted class of probabilities can be given numerical or cardinal magnitudes in Keynes's theory. The vast majority of probabilities are non-numerical in nature, although subsets of these are ordinally comparable. Quantitatively, probabilities are classified into three subsets:

(i) A very small set of numerical probabilities, only occurring in situations of mutually exclusive and exhaustive alternatives when Keynes's principle of indifference holds...

(ii) A large set of non-numerical probabilities which can only be ordinally ranked. 
Consider the second assessment :

"The measurement of probabilities is an intriguing aspect of Keynes's theory. While other theories reduce probabilities to numerical (and hence universally comparable form), Keynes's orderings of the probability space is far more complex. Three types of comparative relations are postulated:

1. Cardinal comparison, which generates the relatively minor class of numerical probabilities. These only exist under the restrictive condition of equi-probability, which is established by careful use of the 'principle of indifference'.

2. Ordinal comparison, which generates the much bigger class of non-numerical probabilities. This class consists of many separate, incommensurable series whereby probabilities belonging to the same series are comparable in terms of greater or lesser, but probabilities belonging to different series are generally incapable of being compared in magnitude.

3. Non-comparability, which typically exists between numerical and non-numerical probabilities, and between non-numerical probabilities in different series"(O’Donnell,2006,pp.361-362)

O'Donnell's entire analysis rests on a complete misconstrual of Keynes's chapter III analysis of interval probability in the TP , as well as Keynes's later analysis contained in chapters $5,7,10,15,16,17,20,22$, and 26 of the TP.

First, Keynes's non-numerical probabilities are identical to Boole's constituent probabilities. Second, ““'The sphere of inexact numerical comparison is not, however, quite so limited. Many probabilities, which are incapable of numerical measurement, can be placed nevertheless between (Keynes's emphasis) numerical limits".(Keynes, TP ,pp.160-161;author's emphasis )

If many probabilities can be specified using intervals, then few cannot .

Third, it is impossible to specify any role for weight of evidence if one is only able to use ordinal probability.

Fourth, complete and total uncertainty exists (this is O'Donnell's irreducible uncertainty)if,and only if, if $w=0$,i.e. Keynes's "We simply do not know" comment. For any probability with $w>0$, then

"The results of our endeavours are very uncertain, but we have a genuine probability, even when the evidence upon which it is founded is slight. The matter is truly stated by Bishop Butler: "From our short views it is greatly uncertain whether this endeavour will, in particular instances, produce an overbalance of happiness upon the whole; since so many and distant things must come into the account. And that which makes it our duty is that there is some appearance that it will, and no 
positive appearance to balance this, on the contrary side. ..."* The difficulties which exist are not chiefly due, I think, to our ignorance of the remote future."(Keynes,TP,1921, p.310).

Thus, there is no such thing as O'Donnell's imaginary "probabilistic uncertainty". Uncertainty ,as was first pointed out by Adam Smith, deals only with the information that a probability estimate is based on. Keynes made it very clear in chapter 6 of the TP that weight is completely independent of probability. Since Keynes's definition of uncertainty on p.148 of the General Theory is that it is a function only of weight,it is impossible for O'Donnell's imaginary probabilistic uncertainty to be a part of Keynes's approach.

Wilson's 1934 paper allows one to conclude that practically all of the published work of Skidelsky, Runde, Carabelli, O'donnell , Meeks,etc.,that claims to deal with Keynes approach in the TP makes no sense.All of these authors claims about Keynes's ordinal probabilities makes no sense.

\section{Section 3.Conclusion}

Wilson, after failing to understand what Keynes was doing in the TP in his 1923 review, finally figured out what Keynes's technical apparatus was in 1934.It took Wilson 11 long years to comprehend Keynes's system of analysis. However, he never figured out why Keynes was dealing with uncertainty because he could only comprehend situations of risk.This is a major problem with practically all statisticians, who believe that they are dealing with complete evidence sets of data and information.

The Keynesian fundamentalists do not know or understand what Wilson understood in 1934.It is mathematically impossible for Keynes's approach to be an ordinal approach which, according to Skidelsky and Meeks, could only be used part of the time. This follows from the fact that the Keynesian Fundamentalists are mathematically illiterate, mathematically innumerant, and mathematically inept.

\section{References}

Arthmar, Rogério \& Brady, Michael Emmett.(2016) .The Keynes-Knightand the de Finetti-Savage's Approaches to Probability: an Economiclnterpretation. History of Economic Ideas, Vol.XXIV,no.1,pp.105-124.

Bateman, Bradley.(2003).The end of Keynes and philosophy? In Runde, J. \& Mizuhara, S. (Eds ). (2003). The Philosophy of Keynes' Economics. London: Routledge.

Boole, George. (1854). An Investigation of the Laws of Thought on Which are Founded the Mathematical Theories of Logic and Probability. New York: Dover Publications, [1958].

Brady, Michael Emmett .(1996) .Decision Making Under Risk in the Treatise on Probability: J.M. Keynes' 'Safety First' Approach, History of Economics Review, 25, pp. 204-210, 1996. 
Brady, Michael Emmett .(1997).Decision Making Under Uncertainty in the Treatise on Probability: Keynes' Mathematical Solution of the 1961 Ellsberg Two Color, Ambiguous Urn Ball Problem in 1921, History of Economics Review, 26, pp. 136-142, 1997.

Brady, Michael Emmett .(1997).The Development of Keynes' Theories of Risk: Chapters 26 and 29 of the Treatise on Probability", History of Economics Review, 26, pp. 143-145, 1997

. (2004a). J. M. Keynes' Theory of Decision Making, Induction, and Analogy. The Role of Interval Valued Probability in His Approach. Philadelphia, Pennsylvania: Xlibris Corporation.

. (2004b). Essays on John Maynard Keynes and .... Philadelphia, Pennsylvania: Xlibris Corporation.

Brady, Michael Emmett and Arthmar,Rogerio.2012.Keynes,Boole, and the Interval approach to Probability. History of Economic Ideas, 20,3, pp.65-84.

Carabelli , Anna. (1988). On Keynes' Method. New York, St. Martins Press.

Carabelli A. 1994, Keynes on mensuration and comparison, in K.Vaghn ed, Perspectives in the History of EconomicThought, Aldershot, Edward Elgar, 1994, pp. 204-38

Carabelli, Anna, 1995. Uncertainty and measurement in Keynes: probability and organicness in Dow, Sheila; Hillard,John, (eds.) Keynes, Knowledge and Uncertainty. Aldershot: Edward Elgar.

Carabelli A. 2009, "Economic theory after Keynes: a new methodological approach", University of Stirling, SCEME working papers.

Carabelli , Anna.(2003).Keynes: economics as a branch of probable logic. In Runde, J. \& Mizuhara, S. (Eds). (2003). The Philosophy of Keynes' Economics. London: Routledge.

Dow, Shiela.(2003).Probability, uncertainty and convention: economists' knowledge and the knowledge of economic actors. In Runde, J. \& Mizuhara, S. (Eds). (2003). The Philosophy of Keynes' Economics. London: Routledge.

Davis, John. (2003).The relationship between Keynes's early and later philosophical thinking. In Runde, J. \& Mizuhara, S. (Eds). (2003). The Philosophy of Keynes' Economics. London: Routledge.

Edgeworth, F. Y. 1884. Philosophy of Chance. Mind 9:223-35.

-1905. The Law of Error. Transactions of the Cambridge Philosophical Society 20:36-65, 113-41.

- 1922a. The Philosophy of Chance. Mind, new ser., 31:257-83.

- 1922b. A Treatise on Probability, by John Maynard Keynes. Journal of the Royal Statistical Society 85:107-13.

Edgeworth, Francis Y. (1922). "A Treatise on Probability by John Maynard Keynes," Journal of the Royal Statistical Society,85,no.1,pp.107-113.

Ellsberg, Daniel.(2001). Risk, Ambiguity and Decision (Studies in Philosophy).England; Routledge. 
Fioretti, Guido.(2003). No faith, no conversion: the evolution of Keynes's ideas on uncertainty under the influence of Johannes von Kries. InRunde, J. \& Mizuhara, S. (Eds). (2003). The Philosophy of Keynes' Economics. London: Routledge.

Fitzgibbons, Athol.(2003).Keynes's epistemology. In Runde, J. \& Mizuhara, S. (Eds). (2003). The Philosophy of Keynes' Economics. London: Routledge.

Gerrard, Bill.(2003).Keynesian uncertainty: what do we know? In Runde, J. \& Mizuhara, S. (Eds). (2003). The Philosophy of Keynes' Economics. London: Routledge.

Gillies, Donald.(2003). Probability and uncertainty in Keynes's The General Theory.InRunde, J. \& Mizuhara, S. (Eds). (2003). The Philosophy of Keynes' Economics. London: Routledge.

Keynes, J.M.(1921).A Treatise on Probability.London;Macmillan.

Keynes, J. M. (1921). A Treatise on Probability. The Collected Writings of John Maynard Keynes (CWJMK) vol. VIII. London: Macmillan, 1973.

. F. P. Ramsey. In Essays in Biography, CWJMK (pp. 335-346), vol. X, London: Macmillan for the Royal Economic Society (reprinted from The New Statesman and Nation, 3 October 1931).

Keynes, J.M. (1921). A Treatise on Probability. London: Macmillan.

Keynes, J.M. (1937). “The General Theory of Employment”. Quarterly Journal of Economics 51: pp. 209-223.

Keynes, J.M. ( 1964). The General Theory of Employment, Interest and Money, New York: Harcourt, Brace and World.

Keynes, J.M. (1972). Essays in Biography. Vol. X, The Collected Writings of John Maynard Keynes (CWJMK), D. Moggridge (ed.). London: Macmillan.

Lawson, Tony.(2003).Keynes's realist orientation. .In Runde, J. \& Mizuhara, S. (Eds). (2003). The Philosophy of Keynes' Economics. London: Routledge.

Marzetti Dall'Aste Brandolini, Silvia and Scazzieri, Roberto.(2011).Fundamental Uncertainty. England;Palgrave Macmillan.

McCann, Jr., Charles.(2003).On the nature of Keynesian probability. In Runde, J. \& Mizuhara, S. (Eds). (2003). The Philosophy of Keynes' Economics. London: Routledge.

Mellor, D.H. (1995). “E.P. Ramsey”, Philosophy, 70, pp. 243-257.

Meeks, Gay T.(2003).Keynes on the rationality of decision procedures under uncertainty: the investment decision. In Runde, J. \& Mizuhara, S. (Eds). (2003). The Philosophy of Keynes' Economics. London: Routledge.

O'Donnell, Rod.(2003). The thick and the thin of controversy. In Runde, J. \& Mizuhara , S. (Eds). (2003). The Philosophy of Keynes' Economics. London: Routledge. 
O'Donnell, Rod.(2012).Treatise on Probability. In The Elgar Companion to POST KEYNESIAN ECONOMICS, ed. By J E King. England ; Edward Elgar,pp.359-365.

O'Donnell, Rod. (2014). "Two Post-Keynesian Approaches to Uncertainty and Irreducible Uncertainty," in G. C. Harcourt and Peter Kriesler (eds.), The Oxford Handbook of Post-Keynesian Economics. Volume 2: Critiques and Methodology. Oxford University Press, New York. pp. 124-142.

Runde, J. andMizuhara, S., (eds.)(2003). The Philosophy of Keynes' Economics: Probability, Uncertainty, and Convention. London: Routledge.

Runde,J. \& Mizuhara,S.(2003).Introduction. . In Runde, J. \& Mizuhara, S. (Eds). (2003). The Philosophy of Keynes' Economics. London: Routledge.

Russell, B. 1922. Review of A Treatise on Probability, by J. M. Keynes. Mathematical Gazette, Volume 11,No.159,(July,1922),pp.119-25.

246 Shackle, G L S. (1983/84). The romantic mountain and the classic lake: Alan Coddington's Keynesian Economics. Journal of Post Keynesian Economics, Winter, Vol. 6 , Issue 2, pp .241-.

Shackle, G.L.S.(1984). Comment on the papers by Randall Bausor and Malcolm Rutherford. Journal of Post Keynesian Economics ,Spring, Vol. 6, Issue 3, pp 388-394.

Skidelsky, Robert, (1983). John Maynard Keynes: Hopes Betrayed (1883-1920). Vol. I. London: MacMillan.

Skidelsky, R. (1992). John Maynard Keynes, Volume II: The Economist as Saviour 1920-1937. London: Macmillan.

Skidelsky, Robert.(2010).The Social Market Economy Revisited.The Social Market Foundation.London, England.

Wilson, E. B. (1923).Keynes on Probability. Bulletin of the American Mathematical Society, 29, no.7, pp.319-322.

Wilson, E. B. (1934). Boole'e Challenge Problem. Journal of the American Statistical Association,vol.29,No.187,pp.301-304.

Winslow, Elliot.(2003). The foundations of Keynes's economics. In Runde, J. \& Mizuhara, S. (Eds). (2003). The Philosophy of Keynes' Economics. London: Routledge. 